\title{
Editorial: Innovating in Times of Crisis
}

\author{
Stoyan Tanev, Editor-in-Chief and Gregory Sandstrom, Managing Editor
}

Welcome to the September issue of the Technology Innovation Management Review. This month features the first two of several papers in upcoming issues from the 31st ISPIM Innovation Conference, which had the theme "Innovating in Times of Crisis", and was held virtually on June 7-8th, 2020. Our ongoing cooperation with the International Society for Professional Innovation Management offers the opportunity for the Editorial Board to select highly relevant articles in particular research domains and invite submissions that undergo the usual double blinded peer review process resulting in the selection of high quality contributions of interest to our readers. Three other papers add further contributions based on current research focusing on the strategic aspects of business intelligence, smarter cities, and the social acceptance of cleaner energy.

Tiago Filipe Pereira da Silva and João Paulo Coelho Marques start the issue with "Human-Centered Design for Collaborative Innovation in Knowledge-based Economies". They describe case study research they did on a university-industry collaboration based on a course project associated with Stanford University's ME310 Design Innovation program. The case focuses on the Porto Design Factory at the Polytechnic Institute of Porto, and IKEA Industry joining forces to tackle a problem using project-based learning. The students involved made use of human-centred design principles in new product development through direct exposure to a specific industrial environment and the knowledge facilities associated with their course of study. The innovative project resulted in the development of the LÄNK Technology, along with nine other prototypes, coming out of this combination of approaches used in an applied classroom-industry setting. Their aim was to lead to "stimulating co-creation, and solving companies' problems by involving students and professionals in a mutual learning process" (pg. 13).

Next, Priscilla Kan John, Emmaline Lear, Patrick L'Espoir Decosta, Shirley Gregor, Stephen Dann, and Ruonan Sun present "Designing a Visual Tool for Teaching and Learning Front-End Innovation (FEI)". As part of their research, the authors designed and developed a guided visual tool that they call the "project client map" (PCM), which is "intended to assist students in their class projects solving real-world problems with industry clients" (pg. 16). The case study for the paper involves the artefact development and evaluation of the PCM in a classroom setting, as the researchers begin to develop their new visual tool. The authors present it as a way for "teaching Master-level students how to solve unstructured real-world industry challenges through their project work", and as "a visual mapping tool for problem formulation and identification as part of tackling FEI" (pg. 24). This route to addressing problematization follows that of evidence-based teaching and learning, along with using both "design thinking" and "design science research" methods.

After that, Yassine Talaoui, Marko Kohtamäki, and Risto Rajala are found 'Seeking 'Strategy' in Business Intelligence Literature: Theorizing BI as part of strategy research". They conducted an in depth literature review and identified a gap regarding how BI and competitive intelligence work together with respect to strategic thinking. They discovered previously unlinked literature that connects BI with strategy research and practice. Their paper offers a re-conceptualization of BI as a strategic artifact according to four clusters: BI as a system, BI as a planned process, BI as a product, and BI as a decisional paradigm. The aim of the authors is "to encourage a change in perspective for researchers to adopt a more comprehensive view of BI aimed at facilitating real time decision making and strategic learning" (pg. 35).

Haven Allahar continues with, "What are the Challenges of Building a Smart City?" After providing a brief background of the "smart city" concept, including its various attributes and distinguishing features, the author looks at smart city initiatives, including the importance of having an ICT plan as part of a smart city's characteristics. For a use case with which the author is closely familiar, he focuses on the Port of Spain's efforts to become a "smart city", or at least to become "smarter". The paper shows the difficulties and barriers to smart city planning, outlining both the ideals to strive for in smart city development, as well as the easy ways to fall short with confusing, unrealistic, or over-estimated smartification dreams. The paper concludes that "there is no single route to becoming a smart city" (pg. 38). Nevertheless, "there are critical steps that can be adopted as part of a building process for achieving that objective" (Ibid). The paper provides multiple insights from the literature recommended for smarter city development, including policy proposals, thus containing implications for both city builders and researchers. 


\section{Innovating in Times of Crisis}

\section{Stoyan Tanev and Gregory Sandstrom}

The edition concludes with Mika Westerlund's "Social Acceptance of Wind Energy in Urban Landscapes", noting the Canadian government's recent call for a green, inclusive "restart" of the economy in its post-COVID-19 recovery plan. Exploring the scenarios of the possibility for an accelerated transition to renewable energy systems, this article raises social awareness issues related to clean energy and sustainability planning for cities. The author focuses on wind energy, based on data collected from residents of the city of Helsinki, Finland. The paper outlines various factors affecting the social acceptance of wind energy and distinguishes three groups in terms of level of acceptance: Protagonists, Centrists, and Antagonists. The findings include that "gender demographics matter for wind energy acceptance" (pg. 57), where the survey results revealed that, "in the Finnish urban context, women come out as more supportive of wind energy than men" (Ibid). The research likewise upholds the established understanding that, for example, of wind turbine visibility to inhabited city space, "distance matters in wind energy acceptance" (Ibid). The key challenge with wind energy appears to be engagement and willingness to participate in decisionmaking processes, thus taking ownership of the energy challenge.

The TIM Review currently has Calls for Papers on the website for Upcoming Themes with special editions on "Digital Innovations in the Bioeconomy" (Feb. 2021) and "Aligning Multiple Stakeholder Value Propositions" (March 2021). For future issues, we invite general submissions of articles on technology entrepreneurship, innovation management, and other topics relevant to launching and scaling technology companies, and for solving practical problems in emerging domains. Please contact us with potential article ideas and submissions, or proposals for future special issues.

Stoyan Tanev, Editor-in-Chief Gregory Sandstrom, Managing Editor

Citation: Tanev, S. and Sandstrom, G. 2020. Editorial - Innovating in Times of Crisis. Technology Innovation Management Review, 10(9): 3-4. http://doi.org/10.22215/timreview/1390

Keywords: Innovation, new product development, university-industry collaboration, human-centered design, design thinking, co-creation, project-based learning, ME310, front-end innovation, visual tool, problematisation, evidence-based teaching, evidence-based learning, design thinking, business intelligence, competitive intelligence, literature review, strategy as practice, strategy content, strategy process, strategy realms, smart cities concept, smart city initiatives, ICT and smart cities, building smart cities, smart city case studies, social acceptance, wind energy, clean energy, sustainability, city. 